ARTICLE

https://doi.org/10.1038/s41467-019-09486-2 OPEN

\title{
Nucleobase pairing and photodimerization in a biologically derived metal-organic framework nanoreactor
}

Samantha L. Anderson', Peter G. Boyd (10 1, Andrzej Gładysiak1, Tu N. Nguyen', Robert G. Palgrave ${ }^{2}$, Dominik Kubicki ${ }^{3}$, Lyndon Emsley ${ }^{3}$, Darren Bradshaw ${ }^{4}$, Matthew J. Rosseinsky (D) ${ }^{5}$, Berend Smit (i) ${ }^{1} \&$ Kyriakos C. Stylianou (D) ${ }^{1}$

Biologically derived metal-organic frameworks (bio-MOFs) are of great importance as they can be used as models for bio-mimicking and in catalysis, allowing us to gain insights into how large biological molecules function. Through rational design, here we report the synthesis of a novel bio-MOF featuring unobstructed Watson-Crick faces of adenine (Ade) pointing towards the MOF cavities. We show, through a combined experimental and computational approach, that thymine (Thy) molecules diffuse through the pores of the MOF and become base-paired with Ade. The Ade-Thy pair binding at 40-45\% loading reveals that Thy molecules are packed within the channels in a way that fulfill both the Woodward-Hoffmann and Schmidt rules, and upon UV irradiation, Thy molecules dimerize into Thy<>Thy. This study highlights the utility of accessible functional groups within the pores of MOFs, and their ability to 'lock' molecules in specific positions that can be subsequently dimerized upon light irradiation, extending the use of MOFs as nanoreactors for the synthesis of molecules that are otherwise challenging to isolate.

\footnotetext{
${ }^{1}$ Laboratory of Molecular Simulation (LSMO), Institut des Sciences et Ingénierie Chimiques (ISIC), École Polytechnique Fédérale de Lausanne (EPFL Valais Wallis), Rue de I'Industrie 17, CH-1951 Sion, Switzerland. ${ }^{2}$ Department of Chemistry, University College London, 20 Gordon St, London WC1H 0AJ, UK. ${ }^{3}$ Laboratory of Magnetic Resonance (LRM), Institut des Sciences et Ingénierie Chimiques (ISIC), École Polytechnique Fédérale de Lausanne (EPFL), CH-1015 Lausanne, Switzerland. ${ }^{4}$ School of Chemistry, University of Southampton, Highfield Campus, Southampton SO17 1BJ, UK. ${ }^{5}$ Department of Chemistry, University of Liverpool, Crown Street, Liverpool L69 7ZD, UK. Correspondence and requests for materials should be addressed to K.C.S. (email: kyriakos.stylianou@epfl.ch)
} 
$\mathrm{T}$ he structural versatility, permanent porosity, tunable pore surfaces, and periodic nature of metal-organic frameworks (MOFs) provide a unique opportunity to study their potential in applications ranging from gas storage and separation, to UV-induced coupling, catalysis, and sensing ${ }^{1-7}$. Biologically-derived MOFs (bio-MOFs) based on ligands such as amino acids, nucleobases, and oligosaccharides have shown a great potential in many research areas as they can be used as models for bio-mimicking and catalysis ${ }^{8,9}$. There is a significant interest in observing biological phenomena in porous bio-MOFs, as we can gain insights into their response upon the inclusion of guest molecules and how guest molecules behave within these confined spaces ${ }^{8-15}$. These insights can ultimately lead into the generation of novel bio-MOFs with tunable pore functionalization, allowing one to target specific chemical reactions and isolate desired products ${ }^{16-19}$. This has the potential to open up a new field of research related to drug design, discovery, delivery, and catalysis ${ }^{20,21}$.

Exploiting functional pore surface in MOFs has recently been utilized in carbohydrate separation and labeling and photochemical transformations $s^{22-24}$. Intrigued by the pore surface interactions with guest molecules, and the use of functional groups as structure-directing agents, herein we investigated the Watson-Crick (W-C) face of adenine (Ade) within a new MOF (hereafter called as SION-19) for nucleobase pairing with thymine (Thy), and solid-state photodimerization of Thy to Thy<>Thy, a molecule that is related to skin cancers such as melanoma ${ }^{25}$. For this concept, two prerequisites govern both the ability of the MOF to act as a nanoreactor, and the ability of Thy to undergo dimerization. First, the strength of Ade-Thy nucleobase pairing within the pores of the MOF is determined by its pore shape and size. Thy not only needs to be able to fit within the pore, but an optimal distance of $<3 \AA$ between Ade-Thy is required to allow for the formation of $\mathrm{H}$-bonds via the $\mathrm{W}-\mathrm{C}$ face of Ade ${ }^{26}$. Here, the structure directing ability of Ade within SION-19 can 'lock' Thy into a position close enough to another Thy for photodimerization to occur. Second, for successful dimerization, both the Woodward-Hoffmann and Schmidt rules would have to be fulfilled ${ }^{27-29}$. This implies that the C5-C6 and C5'-C6' double bonds of Thy (according to its conventional atom numbering scheme) have to be $<4.2 \AA$ apart (center-to-center $)^{29}$ and the molecular orbital symmetry has to be conserved ${ }^{28}$. Ultimately, an overall balance between these requirements is needed, as pores too large or of improper shape can disfavor Ade-Thy base-pair interaction, while incorrect packing of Thy within the pores can affect their ability to dimerize due to poor orientation of the C5-C6 and $\mathrm{C}^{\prime}-\mathrm{C}^{\prime}$ double bonds.

MOFs with unobstructed $\mathrm{W}-\mathrm{C}$ faces of Ade reported in the literature are scarce and the generation of materials with a precise pore aperture for Thy uptake has proven to be challenging ${ }^{17,30,31}$. In addition, the dimerization of Thy and formation of Thy $<>$ Thy has only been achieved either in liquid systems such as freezing water, in the presence of sensitizers such as acetone or when Thy is ordered in DNA struts ${ }^{32-34}$. Inspired by this challenge, and in order to highlight the structural tunability of MOFs, we demonstrate for the first time, that Ade-Thy binding can be achieved within the pores of SION-19, and Thy can be dimerized to Thy<> Thy in solid state at $40-45 \%$ Thy-loadings.

\section{Results}

Crystal structure determination of SION-19. The reaction of $\mathrm{Zn}$ $\left(\mathrm{NO}_{3}\right)_{2} \cdot 6\left(\mathrm{H}_{2} \mathrm{O}\right)$, 1,3,6,8-tetrakis( $p$-benzoic acid) pyrene $\left(\mathrm{H}_{4} \text { TBAPy }\right)^{35,36}$ and Ade in a solvent mixture of $\mathrm{DMF} / \mathrm{H}_{2} \mathrm{O} / \mathrm{HNO}_{3}$ at $120^{\circ} \mathrm{C}$ for $72 \mathrm{~h}$ leads to the generation of yellow truncated rhombic bipyramid crystals. Single-crystal X-ray diffraction (SCXRD) reveals that anionic SION-19, with formula of
$\left[\mathrm{Zn}_{1.5} \mathrm{O}_{0.25}(\mathrm{Ade})(\mathrm{TBAPy})_{0.5}\right]\left(\mathrm{NH}_{2} \mathrm{Me}_{2}\right)_{0.5} \cdot(\mathrm{DMF})_{0.6} \cdot\left(\mathrm{H}_{2} \mathrm{O}\right)_{4.0}$, crystallizes in an orthorhombic unit cell with the Ccce spacegroup symmetry and cell parameters of $a=10.7402(3) \AA$, $b=30.6236(7) \AA, c=42.6282(11) \AA, \alpha=\beta=\gamma=90^{\circ}$ with $V=$ 14020.6(6) $\AA^{3}$ (Supplementary Discussion 2-3). Within SION-19, octahedral cages are constructed by four Ade ligands and six $\mathrm{Zn}^{\mathrm{II}}$ tetrahedral ions, four of which are in the equatorial plane $\left(\mathrm{Zn}_{\mathrm{eq}}^{\mathrm{II}}\right)$ and two at the apical positions $\left(\mathrm{Zn}^{\mathrm{II}}{ }_{\text {ap }}\right)$ (Fig. 1a). The $\mathrm{Zn}^{\mathrm{II}}{ }_{\text {eq }}$ link the cages by $\mathrm{Zn}_{4} \mathrm{O}$ clusters forming the adeninate columnar building units running along the $a$-axis. The tetrahedral geometry of $\mathrm{Zn}^{\mathrm{II}}$ eq is provided by the $\mathrm{N} 3$ and $\mathrm{N} 9$ atoms from Ade, one $\mu_{4}$-O bridge and one carboxylate $\mathrm{O}$ from a TBAPy ligand. For $\mathrm{Zn}^{\mathrm{II}}$ ap , the tetrahedral coordination environment is owed to two N7 atoms from two adjacent Ade ligands, as well as two monodentate carboxylate $\mathrm{O}$ atoms from two consecutive TBAPy ligands (Fig. 1b). Within SION-19, Ade acts as a deprotonated and bridging tridentate ligand, while the fully deprotonated and disordered TBAPy ligand coordinates in a monodentate fashion from each carboxylate (Supplementary Figure 2). The TBAPy ligands, inclined with respect to the $a$-axis, link the $\mathrm{Zn}^{\mathrm{II}}$-based columnar units to yield a structure expanding in three dimensions. However, due to the geometrical features of these building units and TBAPy, infinite channels endowed with two markedly different chemical character are formed along the $a$-axis. These pores are classified as the acid-pore and the base-pore (Fig. 1c, d). The acid-pore in which the free carboxylate $\mathrm{O}$ atoms from the TBAPy ligand are pointing in, has a pore dimension of $7.9 \AA \times 4.9 \AA$ (including van der Waals radii), while the base-pore contains the unobstructed $\mathrm{W}-\mathrm{C}$ faces of Ade and its dimensions are $5.4 \AA \times 6.9 \AA$ (Fig. 1e). Four Ade ligands attached to the same $\mathrm{Zn}_{4} \mathrm{O}$ cluster point to four different channels, while two Ade linked to the same $\mathrm{Zn}^{\mathrm{II}}$ ap ion are arranged in the antiparallel fashion; therefore, even though all Ade are grouped relatively close to each other within the crystal structure, their spatial orientation allows for all of their W-C faces to be exposed to the channels. These pores, in turn, are occupied by disordered guest solvent molecules and cations that show no indication of preferred location. The accessible volume of SION-19 is $31.3 \%$, and combining the accessible volume with the density of the static structure results in a pore volume of $0.287 \mathrm{~cm}^{3} / \mathrm{g}$. Topological analysis of SION-19 using the TOPOS4.0 software package reveals a new 4,4,8$\mathrm{c}$ net with the point symbol $\left\{4^{2} \cdot 6^{4}\right\} 4\left\{4^{4} \cdot 6^{14} \cdot 8^{10}\right\}^{37}$. This net has been registered in the Topos Topological Database (TTD) collection as $k c s 1$ (Supplementary Figure 3).

Bulk characterization. Powder X-ray diffraction (PXRD), elemental analysis (EA), thermogravimetric analysis (TGA) (Supplementary Discussion 4.1), and solid state ${ }^{13} \mathrm{C}$ CP/MAS NMR confirmed the purity and the structural stability of SION-19. Le Bail fit of the PXRD pattern of SION-19 collected at $298 \mathrm{~K}$ gives refined cell parameters of $a=10.965(7) \AA, b=30.811(2) \AA, c=$ 42.261(6) $\AA, \alpha=\beta=\gamma=90^{\circ}, V=14277.5 \AA^{3}$ (Ccce space-group symmetry, and fit indicators: $R_{\mathrm{wp}}=4.7 \%$ and $\left.\chi^{2}=1.9\right)$ which are in good agreement with the cell parameters obtained by SCXRD (Fig. 2a). The EA revealed that the guest solvent molecules comprise $26.9 \%$ of the mass of SION-19, which is consistent with the TGA mass loss of $27.9 \%$. SION-19 is stable up to $450^{\circ} \mathrm{C}$. Full activation of SION-19 can be achieved upon heating at $110^{\circ} \mathrm{C}$ under dynamic vacuum $\left(10^{-6} \mathrm{mbar}\right)$ for $12 \mathrm{~h}$, giving rise to SION-19' (Supplementary Discussion 4.2). SION-19' is stable in DMF, EtOH, and $\mathrm{CH}_{3} \mathrm{CN}$ solutions, and both as made and desolvated materials are bench top stable for extended periods of time (Supplementary Figure 10). As can be seen in Supplementary Figure 11, SION-19' loses its crystallinity to a significant degree but its PXRD pattern can still be indexed with cell parameters $a=11.048(9) \AA, b=31.268(9) \AA, c=43.140(1) \AA, \alpha=\beta$ 
a

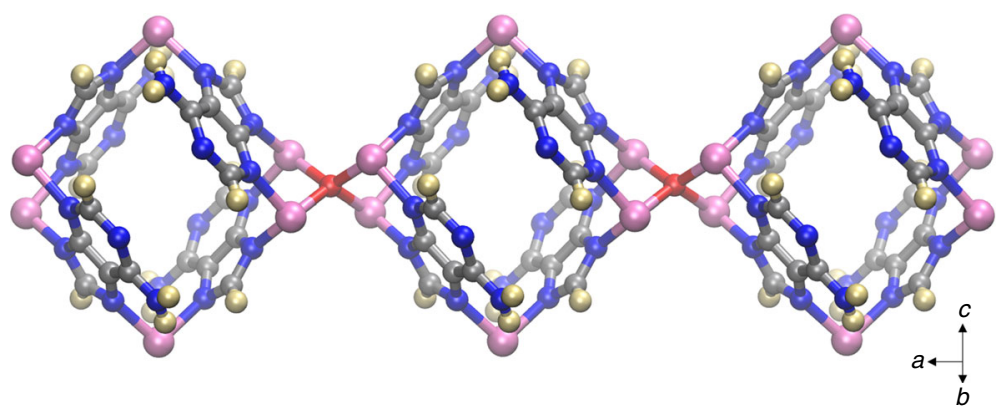

b

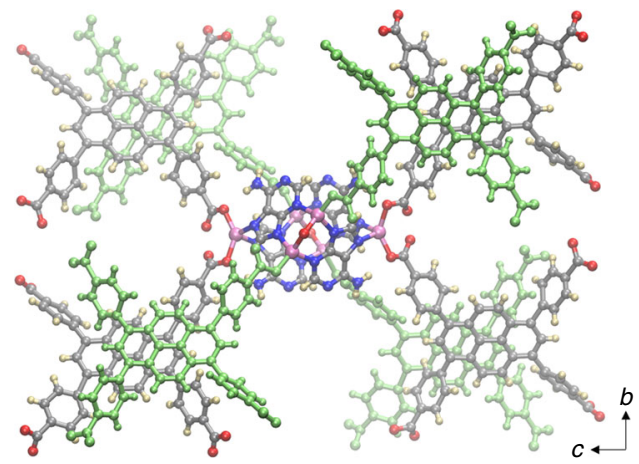

C

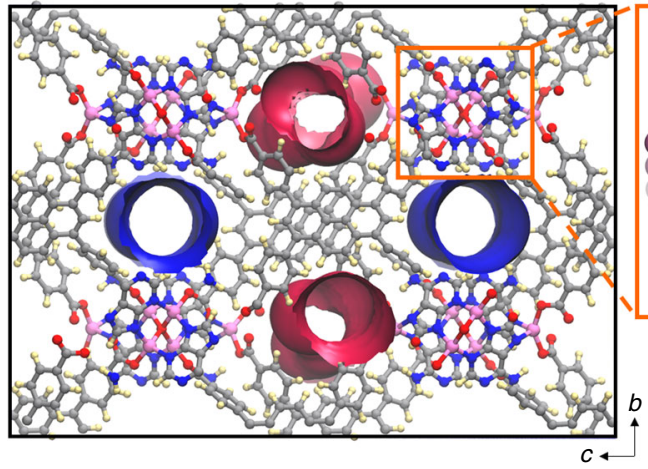

d

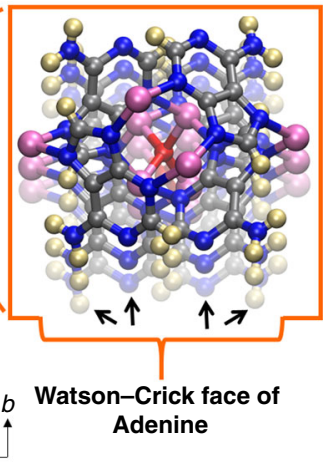

e

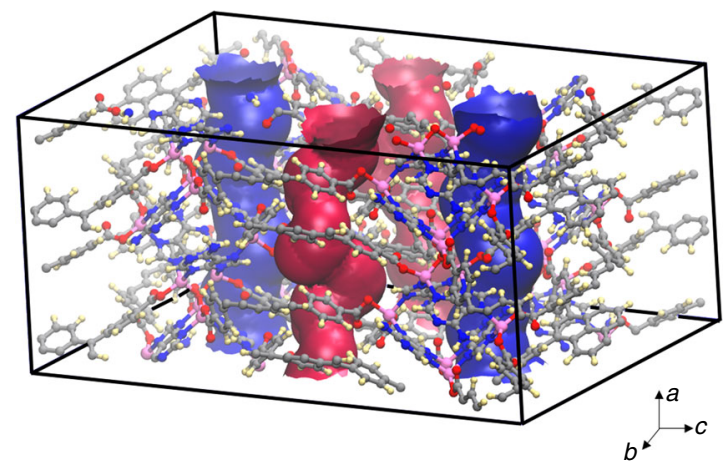

Fig. 1 Structural representation of SION-19. a A Zn" (adeninate) octahedron cage is coordinated to six $\mathrm{Zn}$ " ions, four at the corners of the equatorial plane $\left(\mathrm{Zn}_{\text {eq }}\right)$ and two at the apical positions $\left(\mathrm{Zn}_{\mathrm{ap}}{ }\right)$. The $\mathrm{Zn} \mathrm{n}^{\|}$(adeninate) cages are linked to each other via the $\mathrm{Zn}{ }_{\text {eq }}$ to form 1-dimensional columnar building blocks. $\mathbf{b}$ The $\mathrm{Zn}^{\prime \prime}$ (adeninate) columnar building blocks are linked to each other via fully deprotonated TBAPy ligands-gray TBAPy is bound to $\mathrm{Zn}^{\prime \prime}{ }_{\text {ap }}$ whereas the lime green is bound to $\mathrm{Zn}_{\text {eq }}$. $\mathbf{c}$, $\mathbf{d}$ Connolly surface representation of SION-19 viewed along the $a$-axis, revealing that the coordination of TBAPy ligands to the $\mathrm{Zn}^{\prime \prime}$ (adeninate) columns leads in the formation a 3-dimensional structure possessing two distinct types of 1-dimensional pores: the base-pore (blue) and the acid-pore (red). Highlighted in (d) are the Watson-Crick faces of Ade which point into the base pore and e Connolly surface representation of SION-19 in a 3-dimensional view. Atom color code: pink, Zn; red, O; blue, N; gray, C; light yellow, H

$=\gamma=90^{\circ}, V=14902.6 \AA^{3}$, Ccce space-group symmetry, and fit indicators of $R_{\mathrm{wp}}=4.8 \%$ and $\chi^{2}=2.3$. Both EA and X-ray photoelectron spectra (XPS) collected on H9Ade, $\left[(\mathrm{Me})_{2} \mathrm{NH}_{2}\right] \mathrm{Cl}$ and SION-19' confirm the presence of $\left[\mathrm{NH}_{2} \mathrm{Me}_{2}\right]^{+}$in the pores (Supplementary Discussion 5) which were unable to be directly observed through SCXRD or TGA analyses ${ }^{38}$. To further resolve the location of cations within the pores of SION-19, we performed classical molecular dynamics (MD) simulations which show a clear preference for the $\left[\mathrm{NH}_{2} \mathrm{Me}_{2}\right]^{+}$to localize near the carboxylate groups in the acid-pores of SION-19. This is further supported by the time-averaged energy difference of $14 \mathrm{kcal} / \mathrm{mol} /$ cation in favor of the acid-pore over the base-pore (Supplementary Figure 14).

In order to probe any structural changes upon full activation of SION-19, ${ }^{13} \mathrm{C}$ CP/MAS NMR was utilized. The complete removal of the guest molecules from SION-19 is confirmed by (i) the broadening of the C-signals corresponding to the TBAPy and Ade ligands and (ii) the absence of the carbonyl carbon of DMF at $163.4 \mathrm{ppm}$ (Fig. 2b). The NMR spectrum of SION-19' shows that aliphatic carbons of $\left[\mathrm{NH}_{2} \mathrm{Me}_{2}\right]^{+}$are still present at 31.0 and $35.0 \mathrm{ppm}$ as broad peaks. Combining our findings, it is apparent that the structural backbone of SION-19 is maintained when is activated to SION-19'.

Sorption properties of SION-19'. The permanent microporosity of SION-19' was demonstrated by the type I $\mathrm{N}_{2}$ adsorption isotherm collected at $77 \mathrm{~K}$ and 1 bar (Fig. 2c), and it was also found that SION-19' is porous to $\mathrm{CO}_{2}$ and $\mathrm{CH}_{4}$ at 273 or $298 \mathrm{~K}$ and 1 bar (Supplementary Figure 13). The BET surface area and
Dubinin-Radushkevich pore volume of SION-19' were calculated to be $562(8) \mathrm{m}^{2} / \mathrm{g}$ and $0.246 \mathrm{~cm}^{3} / \mathrm{g}$, respectively. These values are in agreement with the molecular simulations, when $\left[\mathrm{NH}_{2} \mathrm{Me}_{2}\right]^{+}$ species are placed in the acid pores of SION-19' (Supplementary Discussion 7.1). Dynamic $\mathrm{N}_{2}$-probed properties of this simulation report an average void volume of $0.213 \mathrm{~cm}^{3} / \mathrm{g}$ (Supplementary Figure 15) and a surface area of $672 \mathrm{~m}^{2} / \mathrm{g}$ (Supplementary Figure 16). This also confirms the presence of $\left[\mathrm{NH}_{2} \mathrm{Me}_{2}\right]^{+}$in the acid-pore and thus they will not compete with other guest molecules for Ade binding in the base pore.

Thymine loading and dimerization. Based on the structural uniqueness of SION-19 and accessibility of the $\mathrm{W}-\mathrm{C}$ face of Ade pointing towards the base-pore, room temperature Thy solution isotherms were performed in a mixture of EtOH:MeCN solution (20:80) with loadings ranging from 20 to $100 \%$. These loadings were calculated based on the accessible volume of each formula unit in SION-19 (242.0 $\left.\AA^{3}\right)$ and the molecular volume of Thy $\left(142.2 \AA^{3}\right)$. Following a loading of $100 \%$, the equilibrium was established via $\mathrm{UV} /$ vis spectroscopy to be for $24 \mathrm{~h}$ (Fig. 3a, b) ${ }^{39}$. SION-19' can uptake $\sim 1.1$ molecules of Thy at 100\% loading (Fig. 3b, inset), and this is in agreement with the formula derived from EA: $\left.\left[\mathrm{Zn}_{1.5} \mathrm{O}_{0.25} \text { (Ade)(TBAPy }\right)_{0.5}\right]\left(\mathrm{NH}_{2} \mathrm{Me}_{2}\right)_{0.5} \cdot$ (Thy $)_{0.95} \cdot 1.1 \mathrm{E}$ -

$\mathrm{tOH} \cdot 1.5 \mathrm{H}_{2} \mathrm{O}$. Although the crystals of SION-19' lose their singularity which precluded the use of SCXRD for the purpose of SION19@Thy structure determination, the reduced BET surface area: 79 (4) $\mathrm{m}^{2} / \mathrm{g}$ (Supplementary Figure 22), FT-IR (free Thy carbonyl at $1702 \mathrm{~cm}^{-1}$, and at $1699 \mathrm{~cm}^{-1}$ when present in SION-19), and solid state ${ }^{13} \mathrm{C}$ MAS NMR and ${ }^{15} \mathrm{~N}$ CP NMR, which showed 

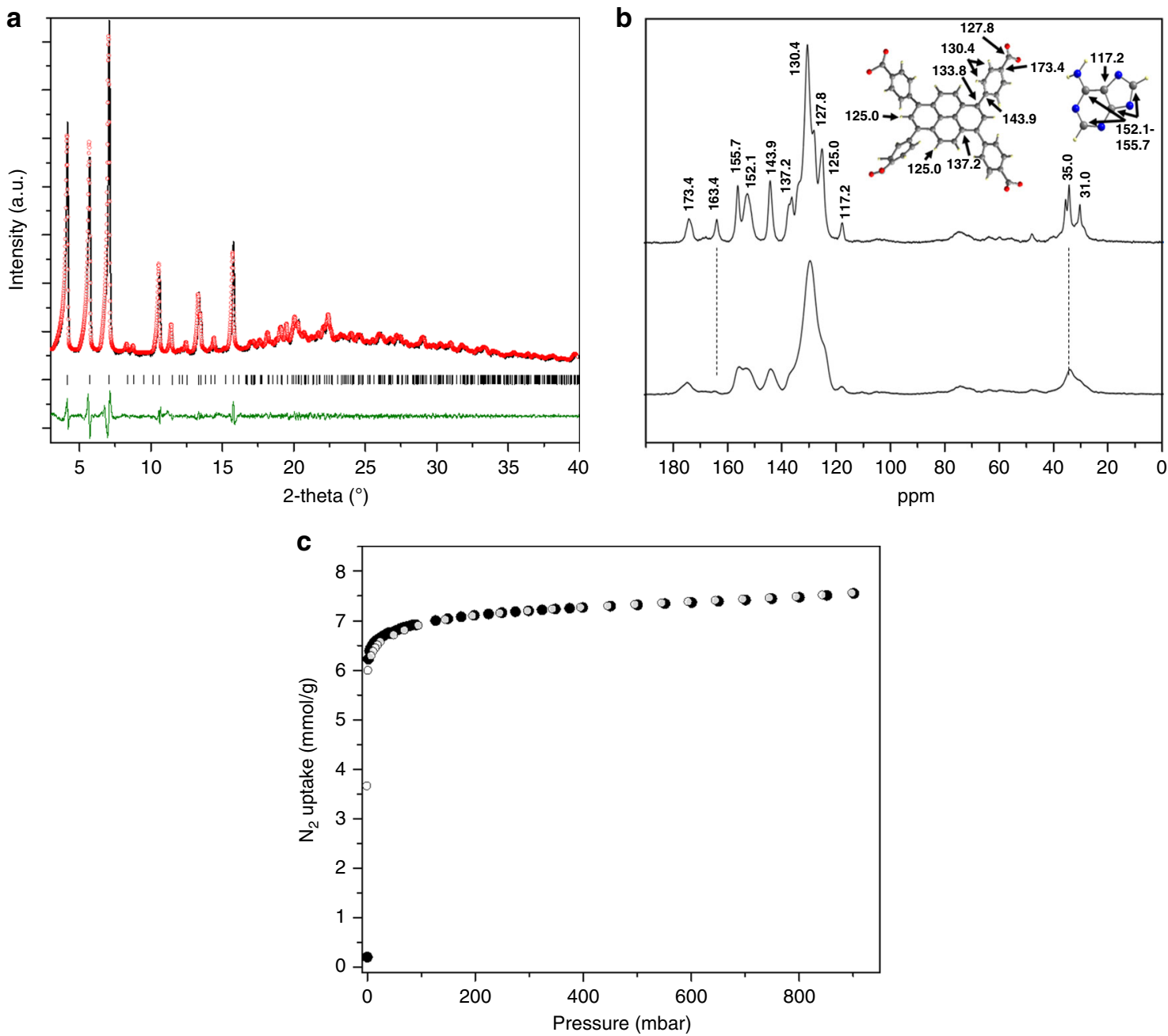

Fig. 2 Solid-state characterization of SION-19 and SION-19'. a Final fit (Rietveld refinement) for a rigid-body structural refinement of the PXRD pattern of SION-19 (final observed: red circles, calculated: solid black lines, and difference: solid green line). b Solid-state ${ }^{13}$ C CP MAS NMR spectra of (top) SION-19 and (bottom) SION-19' collected at $298 \mathrm{~K}$. The assignment of the resonances in SION-19 is consistent with the expected resonances corresponding to the TBAPy and Ade ligands as well as to the DMF and $\left[\mathrm{NH}_{2} \mathrm{Me}_{2}\right]^{+}$molecules residing within the channels. c Type I $\mathrm{N}_{2}$ isotherm measured on SION-19' at $77 \mathrm{~K}$ and 1 bar (filled symbols: adsorption, empty: desorption)

Thy shifts in SION-19@Thy of $\delta 156.1701 \mathrm{ppm}$ (N3), and $\delta$ 126.5180-130.8505 ppm (N1) (Supplementary Discussion 7.2-7.3) confirmed the diffusion of Thy within the pores of SION-19'. Using DFT calculations, EtOH molecules were simulated in the pores of SION-19' and shown to preferentially reside in the acid pores (where no Ade-Thy H-bonding can occur) by $3.3 \mathrm{kcal} / \mathrm{mol}$. This is due to favorable interactions with the charge-balancing cations $\left[\mathrm{NH}_{2} \mathrm{Me}_{2}\right]^{+}$present in the acid pores.

The nature of the Ade-Thy base pair formation in SION-19' was examined through DFT optimization of one Thy near Ade ${ }^{17}$. The optimized distances between $\mathrm{H}$-bonding donors and acceptors are $2.72 \AA\left(\mathrm{N}_{\text {Ade }}-\mathrm{N}_{\text {Thy }}\right)$ and $3.00 \AA\left(\mathrm{N}_{\text {Ade }}-\mathrm{O}_{\text {Thy }}\right)$, and are comparable with the experimentally measured distances of 2.82 and $2.95 \AA$, respectively ${ }^{40}$. In addition, Bader population analysis shows a slight charge polarization of $0.06 \mathrm{e}^{-}$on the heavy atoms $\mathrm{s}^{41}$, indicative of $\mathrm{H}$-bonding formation between Thy and Ade in SION-19'. The DFT binding energy for a single Thy in SION-19' is calculated to be $-18.2 \mathrm{kcal} / \mathrm{mol}$, which has higher absolute value compared to the $\sim-12 \mathrm{kcal} / \mathrm{mol}$ binding energy reported for pure Ade-Thy interactions in both experimental and theoretical calculations ${ }^{42,43}$. Dynamic, finite temperature behavior of Thy within the pores of SION-19' was investigated with classical MD simulations at room temperature $(298 \mathrm{~K})$. In these simulations, base-pair H-bonding was modeled using threebodied potentials using parameters designed for accurate H-bonding in bio-molecules ${ }^{44}$. With this potential, we observe a good energetic agreement with the DFT binding energy computed for Ade-Thy in SION-19', being $1.4 \mathrm{kcal} / \mathrm{mol}$ higher in energy $(-19.6 \mathrm{vs}-18.2 \mathrm{kcal} / \mathrm{mol})$.

Exposure of pyrimidine nucleobases like Thy to UV light can induce a $[2+2]$ cycloaddition between the $\mathrm{C} 5-\mathrm{C} 6$ and $\mathrm{C}^{\prime}-\mathrm{C}^{\prime}$ double bonds of two pyrimidine rings (Supplementary Scheme 1$)^{33}$. While dimerization of Thy in a liquid medium is a viable method to afford Thy<>Thy, its solid-state dimerization has not been fully studied. To confirm this, Thy crystals were exposed to UV light $(254 \mathrm{~nm})$ for $24 \mathrm{~h}$ and ${ }^{1} \mathrm{H}$ NMR revealed that no Thy $<>$ Thy was obtained (Supplementary Figure 27). To investigate the atomistic features of the Thy loading experiments in SION-19', room temperature MD simulations were performed at loadings of $25,44,56,74$, and $100 \%$. Due to the relatively tight pores, and the strong $\mathrm{H}$-bonding potentials used in the simulation, 5 cycles of 2 ns annealing were performed at each loading. Statistics on the orientations of Thy with respect to themselves, and Ade in SION$19^{\prime}$ were collected over the span of $10 \mathrm{~ns}$ at intervals of $2 \mathrm{ps}$. It was hypothesized that in order to enable the formation of Thy<>Thy, the Thy molecules must resemble the transition state of a $[2+2]$ 

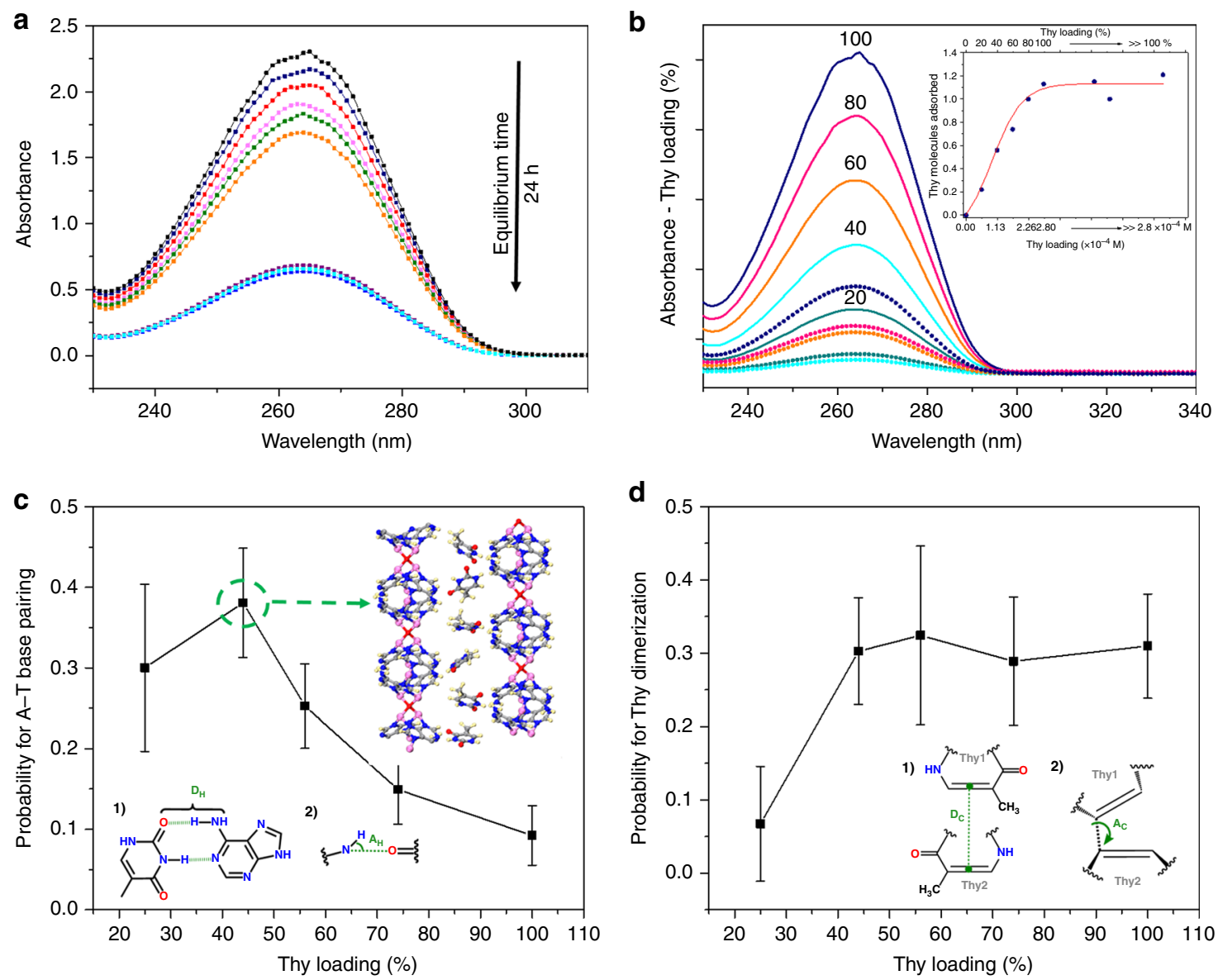

Fig. 3 Solution thymine isotherms in SION-19' and probability of adenine-thymine pairing and thymine-dimerization. a Time dependency for Thy to reach equilibrium when loaded into SION-19'. b Solution isotherms of $20-100 \%\left(0.56-2.80 \times 10^{-4} \mathrm{M}\right)$ Thy loaded into the pores of SION-19'. Inset: maximum uptake of Thy ( $\sim 1.1$ molecules). Here, multiple Thy concentrations (blue circles-above $100 \%$ loading) were used to determine the saturation limit of Thy into the pores of SION-19'. c Frequency of observed Ade-Thy base pair formation from MD simulations-Insets (1) and (2) show the metrics used for H-bonding formation between Ade-Thy from the MD simulations. $\mathbf{d}$ The frequency in which Woodward-Hoffmann and Schmidt rules are satisfied for Thy dimerization in the MD simulations at different loadings. Insets (1) and (2) show the metrics used for satisfying the Woodward-Hoffmann and Schmidt rules

cycloaddition, and follow the Schmidt rules. That is, the C5-C6 and $\mathrm{C}^{\prime}-\mathrm{C} 6^{\prime}$ must be nearly parallel, and separated by $<4.2 \AA^{29}$. Thus, the trajectories for the potential formation of a fourmembered ring were analyzed, specifically when the C5-C6 double bond of adjacent Thy molecules were (i) within $4.2 \AA$ of each other, and (ii) nearly aligned, by determining the dihedral angle formed between $\mathrm{C} 5-\mathrm{C} 6$ and $\mathrm{C}^{\prime}-\mathrm{C}^{\prime}$ is below $30^{\circ 29}$. Figures $3 c, d$ and 4 demonstrate that Thy molecules appear to be more favorably oriented for dimerization at $44 \%$ loading and above. This is compared to the peak in base-pair formation, which occurs at a 44\% loading and then subsequently deteriorates. At higher Thy loadings, Thy packs in a dense sterically unfavorable manner within the base pore disfavoring base-pair formation (Fig. 3c). This correlation suggests that the Ade ligands within SION-19' are structure-directing agents, which fix the position of Thy within the pores, and can allow for Thy<> Thy formation from two nearby 'locked' base-paired Thy molecules. A plot of the trajectories at a $44 \%$ loading show that Thy molecules form base pairs with Ade that are two Ade units apart along the $a$-axis, and on opposite sides of the pore (Fig. 3d). To validate this experimentally, samples of SION-19@Thy (20-80\%) were continuously exposed to UV for $24 \mathrm{~h}^{45}$. The formation of Thy $<>$ Thy was determined via ultra-high performance liquid chromatography coupled with electrospray ionization mass spectrometry (UHPLC-ESI/MS) (Supplementary Discussion 8.4-8.4.1). Samples of SION-19@UV-Thy(20-30, 50-80\%) (Supplementary Figures 35) showed no presence of product, while SION-19@UV-Thy(40-45\%) (Supplementary Figure 36-41) afforded Thy $<>$ Thy in a non-quantitative yield (58.5\%). The non-quantitative nature of this dimerization is thought to be due (i) to the low population of an excited state (singly excited, ${ }^{1} \mathrm{SE}$ ), which proceeds through an internal conversion, and requires overcoming an energy barrier ${ }^{27}$, and (ii) to the poor penetration of light throughout the solid material, and thus some Thy molecules do not have enough energy to overcome this barrier and dimerize. Here, this mechanism is governed by both conformational control, and electronic effects $^{27-29}$. The inability of lower Thy loadings $(20-30 \%)$ to dimerize might be due to the increased spatial distance between Thy molecules as they slowly diffuse through the channels, while at higher loadings $(50-80 \%)$, there is a decrease of H-bonding stabilization between the framework Ade and Thy, leading to an unfavorable packing within the base-pore.

\section{Discussion}

To further confirm the structural uniqueness of SION-19' to 'lock' Thy into a specific orientation and transfer energy for dimerization, Thy loading and dimerization in the pores of adenine-containing 
a

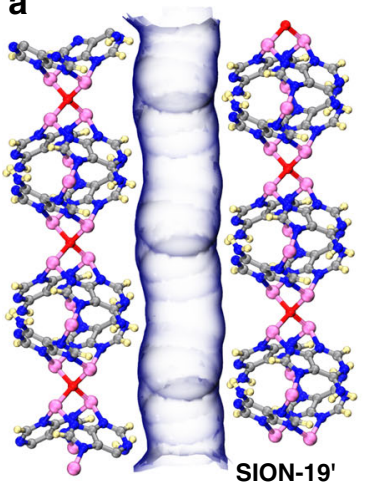

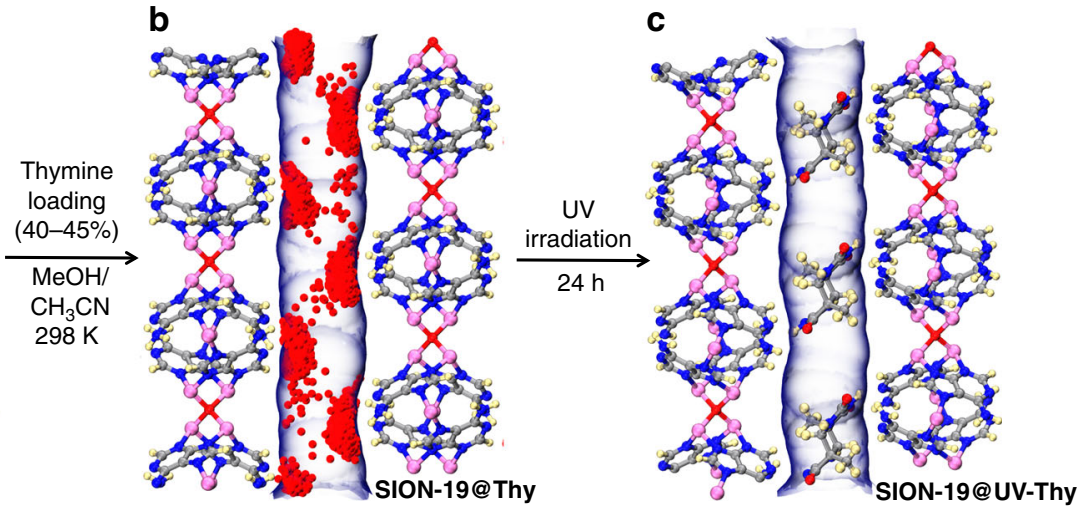

c

Fig. 4 Schematic representation of thymine loading, location, and dimerization within SION-19'. a 1-dimensional base-pore surface for SION-19' prepared using HOLE2. b Thy snapshots (red dots) from an MD trajectory of $44 \%$ thymine loading in the base pore of SION-19. Here, Ade acts as a structure directing agent that 'lock' Thy molecules into positions close enough to another Thy molecule for photodimerization to occur. c DFT optimized positions of Thy<> Thy dimers arising from a $44 \%$ loading of Thy. Atom color code: pink, Zn; red, O; blue, N; gray, C; light yellow, H

bio-MOF-1 as well as HKUST-1 and Zn-MOF-74, which are not adenine-based, were attempted, and in all cases no traceable amounts of Thy<>Thy were observed (Supplementary Discussion 9). These results further confirm that not only the presence of the $\mathrm{W}-\mathrm{C}$ faces of Ade, but also the optimal Ade-Thy binding ratio and the subsequent electronic effects/conformation control, play an important role in the dimerization process. That is, the stabilization of Thy via $\mathrm{W}-\mathrm{C}$ H-bonding with Ade in SION-19 allows it to conform to both the Schmidt and Woodward-Hoffmann rules.

In conclusion, we synthesized a novel biologically derived MOF, SION-19, possessing a new $k c s 1$ topology and Adefunctionalized pore surface, that acts as a nanoreactor for the dimerization of Thy via site-specific binding to Ade. We successfully showed that the orientation of Ade within SION-19 permits Thy binding (40-45\% loading) that resembles the transition state of $[2+2]$ cycloaddition required for Thy dimerization. Thy loading and dimerization in the pores of SION-19, and the specific relationship between Ade-Thy binding demonstrate that taking advantage of functional groups that decorate the pore surface of MOFs can be used as an effective strategy for their utilization as nanoreactors for photo-induced organic reactions.

The ability to photo-induce the dimerization of solid state Thy within the constrained pores of SION-19 can ultimately provide new fundamental insights on the governing mechanism of this process. Our approach can be applied to a variety of MOFs or other porous materials with comparable structural features to 'lock' molecules in specific positions, and can open up new avenues for the synthesis of organic molecules that may otherwise be difficult to obtain through traditional routes. Furthermore, using bio-MOFs as nanoreactors to form biologically relevant molecules can bridge multiple research disciplines, which can aid in the development of new methods for drug discovery and delivery. These strategies can offer an opportunity for interdisciplinary work, that is, to develop new synthetic methodologies and study the activity of new bio-related products.

\section{Methods}

Synthesis of SION-19, thymine loading, and photodimerization. Reagents and solvents were purchased from Sigma-Aldrich $\left(\mathrm{Zn}\left(\mathrm{NO}_{3}\right)_{2} \cdot 6\left(\mathrm{H}_{2} \mathrm{O}\right)\right)$, TCI (Ade), and Carl Roth (DMF) and used without further purification.

SION-19 was synthesized through the combination of $\mathrm{Zn}\left(\mathrm{NO}_{3}\right)_{2} \cdot 6\left(\mathrm{H}_{2} \mathrm{O}\right)(17 \mathrm{mg}$, $0.057 \mathrm{mmol}), \operatorname{TBAPy}^{35}(10 \mathrm{mg}, 0.0146 \mathrm{mmol})$ and Ade $(8 \mathrm{mg}, 0.059 \mathrm{mmol})$, in an acidic DMF: $\mathrm{H}_{2} \mathrm{O}: \mathrm{HNO}_{3}$ ( $5.5 \mathrm{~mL}: 0.5 \mathrm{~mL}: 4$ drops). The vial is then capped and placed in the oven for $72 \mathrm{~h}$ at $120^{\circ} \mathrm{C}$ with a temperature heating ramp of $2.0^{\circ} \mathrm{C}$, and cooling ramp of $0.2^{\circ} \mathrm{C}$, affording yellow colored truncated rhombic bipyramid like crystals in a $28 \%$ yield (based off of $\mathrm{Zn}$ ). The formula of the 3D framework of SION-19 was

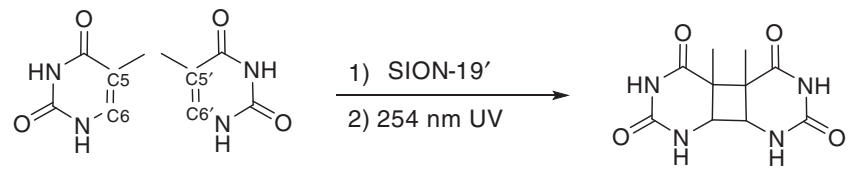

Fig. 5 Thymine photodimerization. Synthetic conditions utilized for the photodimerization of Thy molecules using SION-19'

determined to be $\left.\left[\mathrm{Zn}_{1.5} \mathrm{O}_{0.25} \text { (Ade)(TBAPy }\right)_{0.5}\right]\left(\mathrm{NH}_{2} \mathrm{Me}_{2}\right)_{0.5} \cdot(\mathrm{DMF})_{0.6} \cdot\left(\mathrm{H}_{2} \mathrm{O}\right)_{4.0}$ from SCXRD analysis, while TGA and EA allowed for the determination of the pore content. Anal. Calcd for bulk SION-19 sample [ $\mathrm{Zn}_{1.5} \mathrm{O}_{0.25}$ (Ade)(TBAPy) $\left.{ }_{0.5}\right]$ $\left(\mathrm{NH}_{2} \mathrm{Me}_{2}\right)_{0.5} \cdot(\mathrm{DMF})_{1.7} \cdot\left(\mathrm{H}_{2} \mathrm{O}\right)_{4.0}$ : C 49.95, H 5.05, N 12.67. Experimental: C 50.03, H $4.57, \mathrm{~N} 12.84$. Note: the discrepancies between the chemical composition derived from single crystal and bulk analysis might be due to the bulk sample reflecting the average composition of all crystals.

Desolvation of SION-19 was carried out at $110^{\circ} \mathrm{C}$ under high vacuum $\left(10^{-6}\right.$ mbar). The formula of SION-19' was determined to be $\left[\mathrm{Zn}_{1.5} \mathrm{O}_{0.25}\right.$ (Ade) $\left.(\mathrm{TBAPy})_{0.5}\right]\left(\mathrm{NH}_{2} \mathrm{Me}_{2}\right)_{0.5} \cdot\left(\mathrm{H}_{2} \mathrm{O}\right)_{0.2}$. EA of SION-19': Anal. Calcd for $\left[\mathrm{Zn}_{1.5} \mathrm{O}_{0.25}(\right.$ Ade $\left.)(\text { TBAPy })_{0.5}\right]\left(\mathrm{NH}_{2} \mathrm{Me}_{2}\right)_{0.5} \cdot\left(\mathrm{H}_{2} \mathrm{O}\right)_{0.2}: \mathrm{C} 55.99, \mathrm{H} 3.22, \mathrm{~N} 12.83$. Experimental: C 55.78, H 3.13, N 13.19.

Desolvated ground host material (100 mg), SION-19', was immersed in an EtOH:MeCN (20:80) solution in a Schlenk tube under a $\mathrm{N}_{2}$ atmosphere, which contained a known concentration of Thy. The accessible volume per unit cell for SION-19' is $31.3 \%$ as calculated by MERCURY using the probe radius of $1.2 \AA$ and approx. grid spacing of $0.7 \AA$, therefore the free volume per unit cell is $3872.11 \AA^{3}$. In one unit cell, there are 16 formula units ( $\mathrm{FU}$ : $\left[\mathrm{Zn}_{1.5} \mathrm{O}_{0.25}(\right.$ Ade $\left.)(\mathrm{TBAPy})_{0.5}\right]$ $\left.\left(\mathrm{NH}_{2} \mathrm{Me}_{2}\right)_{0.5}\right)$, resulting in an accessible volume of $242.0 \AA^{3}$ per FU. The volume of a single Thy molecule, calculated from its crystal structure, was found to be $142.219 \AA^{[346}$, and therefore, theoretically 1.70 molecules of Thy can fit per FU of SION-19'. Based on these calculations, the concentration of Thy was varied in order to keep the proportion of filling between 20 and $100 \%\left(0.56-2.80 \times 10^{-4} \mathrm{M}\right)$. SION-19' was also immersed at higher concentrations (up to $7.11 \times 10^{-4} \mathrm{M}$ ) to check the saturation uptake. Through UV-vis, the time dependency for equilibrium of $100 \%$ Thy loading was established to be $24 \mathrm{~h}$. Subsequently, once both the equilibrium time and calibration curve of Thy loaded material were established, SION-19' was loaded with known concentrations of Thy $\left(0.56-2.80 \times 10^{-4} \mathrm{M}\right)$. The absorption of the supernatant was collected and analyzed by UV-vis to quantify the amount of Thy absorbed. Here, the absorption coefficient of thymine in an EtOH:MeCN solution at $263 \mathrm{~nm}$ is $8217 \mathrm{~cm}^{-1} / \mathrm{M}$ which is comparable to that of thymine in $\mathrm{H}_{2} \mathrm{O}\left(7900 \mathrm{~cm}^{-1} / \mathrm{M}\right)^{47}$.

Approximately $50 \mathrm{mg}$ of SION-19@Thy (20-80\% loadings of Thy) is exposed to $\mathrm{UV}$ continuously for $24 \mathrm{~h}$ (Fig. 5). The material was then collapsed in a $6 \mathrm{~mL} 0.5 \mathrm{M}$ $\mathrm{K}_{2} \mathrm{CO}_{3}$ solution, sonicated for $10 \mathrm{~min}$, diluted with $50 \mathrm{~mL}$ of DMSO, and subsequently dried with $\mathrm{MgSO}_{4}$, filtered and concentrated using a rotary evaporator ${ }^{48}$. Each sample was dissolved in $2 \mathrm{~mL}$ of DMSO and further prepared according to the procedure in Supplementary Discussion 7.4 for UHPLC-ESI/MS.

\section{Data availability}

The X-ray crystallographic coordinated for the SION-19 structure reported in this study has been deposited at the Cambridge Crystallographic Data Centre (CCDC), under deposition number 1855564. This data can be obtained free of charge from the Cambridge Crystallographic Data Centre via www.ccdc.ac.uk/data_request/cif. 
Received: 25 October 2018 Accepted: 13 March 2019

Published online: 08 April 2019

\section{References}

1. Eddaoudi, M. et al. Systematic design of pore size and functionality in isoreticular MOFs and their application in methane storage. Science 295, 469-472 (2002).

2. Kong, X. et al. Mapping of functional groups in metal-organic frameworks. Science 341, 882-885 (2013).

3. Li, T. \& Rosi, N. L. Screening and evaluating aminated cationic functional moieties for potential $\mathrm{CO}_{2}$ capture applications using an anionic MOF scaffold. Chem. Commun. 49, 11385-11387 (2013).

4. Lyndon, R. et al. Dynamic photo-switching in metal-organic frameworks as a route to low energy carbon dioxide capture and release. Angew. Chem. Int. Ed. 52, 3695-3698 (2013).

5. Chen, J.-M., Hou, Y.-X., Zhou, Q.-K., Zhang, H. \& Liu, D. UV-induced singlecrystal-to-single-crystal conversion from a coordination ladder to a twodimensional network through an intermolecular carbon-carbon coupling reaction. Dalton Trans. 46, 9755-9759 (2017).

6. Deleu, W. P., Rivero, G., Teixeira, R. F., Du Prez, F. E. \& De Vos, D. E. Metal-organic frameworks encapsulated in photocleavable capsules for UVlight triggered catalysis. Chem. Mater. 27, 5495-5502 (2015).

7. Chen, W.-M. et al. A superior fluorescent sensor for $\mathrm{Al}^{3+}$ and $\mathrm{UO}_{2}{ }^{2+}$ based on a $\mathrm{Co}$ (ii) metal-organic framework with exposed pyrimidyl Lewis base sites. J. Mater. Chem. A 5, 13079-13085 (2017).

8. Anderson, S. L. \& Stylianou, K. C. Biologically derived metal organic frameworks. Coord. Chem. Rev. 349, 102-128 (2017).

9. Zhang, M., Gu, Z.-Y., Bosch, M., Perry, Z. \& Zhou, H.-C. Biomimicry in metal-organic materials. Coord. Chem. Rev. 293-294, 327-356 (2015).

10. Martí Gastaldo, C. et al. Side-chain control of porosity closure in single- and multiple-peptide-based porous materials by cooperative folding. Nat. Chem. 6, 343-351 (2014).

11. Rabone, J. et al. An adaptable peptide-based porous material. Science 329, 1053-1057 (2010).

12. Wright, P. A. Opening the door to peptide-based porous solids. Science 329, 1025-1026 (2010).

13. Imaz, I. et al. Metal-biomolecule frameworks (MBioFs). Chem. Commun. 47, 7287-7302 (2011).

14. Beobide, G., Castillo, O., Luque, A. \& Pérez-Yáñez, S. Porous materials based on metal-nucleobase systems sustained by coordination bonds and base pairing interactions. CrystEngComm 17, 3051-3059 (2015).

15. Beobide, G. et al. Metal-carboxylato-nucleobase systems: from supramolecular assemblies to 3D porous materials. Coord. Chem. Rev. 257, 2716-2736 (2013).

16. Navarro-Sánchez, J. et al. Peptide metal-organic frameworks for enantioselective separation of chiral drugs. J. Am. Chem. Soc. 139, 4294-4297 (2017).

17. Cai, H. et al. Spatial, hysteretic, and adaptive host-guest chemistry in a metal-organic framework with open Watson-Crick sites. Angew. Chem. Int. Ed. 127, 10600-10605 (2015)

18. Mohideen, M. I. H. et al. Protecting group and switchable pore-discriminating adsorption properties of a hydrophilic-hydrophobic metal-organic framework. Nat. Chem. 3, 304 (2011).

19. Stylianou, K. C. et al. Engineering homochiral metal-organic frameworks by spatially separating $1 \mathrm{D}$ chiral metal-peptide ladders: tuning the pore size for enantioselective adsorption. Chem. Eur. J. 21, 9964-9969 (2015).

20. Horcajada, P. et al. Porous metal-organic-framework nanoscale carriers as a potential platform for drug delivery and imaging. Nat. Mater. 9, 172-178 (2010).

21. Ingleson, M. J. et al. Generation of a solid Bronsted acid site in a chiral framework. Chem. Commun. 11, 1287-1289 (2008).

22. Chen, G. et al. Boronic acid decorated defective metal-organic framework nanoreactors for high-efficiency carbohydrates separation and labeling. $A d v$ Funct. Mater. 27, 1702126 (2017).

23. Sapchenko, S. A., Dybtsev, D. N. \& Fedin, V. P. Cage amines in the metal-organic frameworks chemistry. Pure Appl. Chem. 89, 1049 (2017).

24. Todorova, T. K. et al. Molecular level characterization of the structure and interactions in peptide-functionalized metal-organic frameworks. Chem. Eur. J. 22, 16531-16538 (2016)

25. Pfeifer, G. P. \& Besaratinia, A. UV wavelength-dependent DNA damage and human non-melanoma and melanoma skin cancer. Photochem. Photobiol. Sci. 11, 90-97 (2012).
26. Juan-Alcaniz, J., Ramos-Fernandez, E. V., Kapteijn, F. \& Gascon, J. Metal Organic Frameworks as Heterogeneous Catalysts 310-343 (The Royal Society of Chemistry, 2013)

27. Rauer, C., Nogueira, J. J., Marquetand, P. \& González, L. Cyclobutane thymine photodimerization mechanism revealed by nonadiabatic molecular dynamics. J. Am. Chem. Soc. 138, 15911-15916 (2016).

28. Hoffmann, R. \& Woodward, R. B. The conservation of orbital symmetry. Acc. Chem. Res. 1, 17-22 (1968).

29. Schmidt, G. M. J. Photodimerization in the solid state. Pure Appl. Chem. 27, 647 (1971).

30. An, J. et al. Metal-adeninate vertices for the construction of an exceptionally porous metal-organic framework. Nat. Commun. 3, 604 (2012).

31. $\mathrm{Li}$, T. et al. Systematic modulation and enhancement of $\mathrm{CO}_{2}: \mathrm{N}_{2}$ selectivity and water stability in an isoreticular series of bio-MOF-11 analogues. Chem. Sci. 4 1746-1755 (2013)

32. Füchtbauer, W. \& Mazur, P. Kinetics of the ultraviolet-induced dimerization of thymine in frozen solutions. Photochem. Photobiol. 5, 323-335 (1966).

33. Cuquerella, M. C., Lhiaubet-Vallet, V., Bosca, F. \& Miranda, M. A. Photosensitised pyrimidine dimerisation in DNA. Chem. Sci. 2, 1219-1232 (2011).

34. Schreier, W. J. et al. Thymine dimerization in DNA is an ultrafast photoreaction. Science 315, 625-629 (2007).

35. Stylianou, K. C. et al. A guest-responsive fluorescent $3 \mathrm{D}$ microporous metal-organic framework derived from a long-lifetime pyrene core. J. Am. Chem. Soc. 132, 4119-4130 (2010).

36. Stylianou, K. C. Biologically Derived and Pyrene-based Metal-Organic Frameworks for Advanced Applications. PhD thesis, University of Liverpool (2011).

37. Blatov, V. A., Shevchenko, A. P. \& Proserpio, D. M. Applied topological analysis of crystal structures with the program package ToposPro. Cryst. Growth Des. 14, 3576-3586 (2014).

38. Gładysiak, A. et al. Shedding light on the protonation states and location of protonated $\mathrm{N}$ atoms of adenine in metal-organic frameworks. Inorg. Chem. 57, 1888-1900 (2018).

39. Schmuck, C. \& Wienand, W. Self-complementary quadruple hydrogenbonding motifs as a functional principle: from dimeric supramolecules to supramolecular polymers. Angew. Chem. Int. Ed. 40, 4363-4369 (2001).

40. Seeman, N. C., Rosenberg, J. M., Suddath, F. L., Kim, J. J. P. \& Rich, A. RNA double-helical fragments at atomic resolution: I. The crystal and molecular structure of sodium adenylyl-3', $5^{\prime}$-uridine hexahydrate. J. Mol. Biol. 104, 109-144 (1976)

41. Tang, W., Sanville, E. \& Henkelman, G. A grid-based Bader analysis algorithm without lattice bias. J. Phys. Condens. Matter 21, 084204 (2009).

42. Fonseca Guerra, C., Bickelhaupt, F. M., Snijders, J. G. \& Baerends, E. J. Hydrogen bonding in DNA base pairs: reconciliation of theory and experiment. J. Am. Chem. Soc. 122, 4117-4128 (2000)

43. Espejo, C. \& Rey-González, R. Stabilization and interaction energies of non planar DNA base pairs guanine-cytosine and adenine-thymine. A study based on the SIESTA method. Rev. Mex. Fis. 53, 212-216 (2007).

44. Liu, Y., Bryantsev, V. S., Diallo, M. S. \& Goddard Iii, W. A. PAMAM dendrimers undergo $\mathrm{pH}$ responsive conformational changes without swelling J. Am. Chem. Soc. 131, 2798-2799 (2009).

45. Law, Y. K., Azadi, J., Crespo-Hernández, C. E., Olmon, E. \& Kohler, B. Predicting thymine dimerization yields from molecular dynamics simulations. Biophys. J. 94, 3590-3600 (2008).

46. Ozeki, K., Sakabe, N. \& Tanaka, J. The crystal structure of thymine. Acta Crystallogr. B 25, 1038-1045 (1969).

47. Fasman, G. CRC Handbook of Biochemistry and Molecular Biology. (CRC, Cleveland, $\mathrm{OH}, 1975)$.

48. Warren, J. E. et al. Shape selectivity by guest-driven restructuring of a porous material. Angew. Chem. Int. Ed. 53, 4592-4596 (2014).

\section{Acknowledgements}

The authors acknowledge the financial support from the Swiss National Science Foundation (SNF) under the Ambizione Energy Grant No. PZENP2_166888, the European Research Council (ERC) Advanced Grant (Grant Agreement No. 666983, MaGic) and the Materials' Revolution: Computational Design and Discovery of Novel Materials (MARVEL), of the Swiss National Science Foundation (SNSF) -DD4.5. K.C.S. and M.J.R. thank EPSRC for funding; the material studied here was first synthesized at the University of Liverpool, supported by EPSRC under EP/C511794. The authors thank SNBL at ESRF for accessing BM01 for single-crystal X-ray diffraction. The Swiss National Supercomputing Center (CSCS) under Project No. s611 supported this work. The authors would also like to thank Dr. Natalia Gasilova for her help with the UHPLC-ESI/MS.

\section{Author contributions}

S.L.A. and K.C.S. performed the experiments and analyzed the data. P.G.B. performed and analyzed the molecular simulations and discussed the data with B.S. A.G. and T.N.N. 
collected the X-ray data, performed the analysis, and participated in the interpretation of the results for Thy<>Thy formation. D.K. performed the solid-state NMR experiments and analyzed the data with L.E. K.C.S. discussed the project with D.B., M.J.R., and B.S. and designed the experiments for Thy dimerization. K.C.S. conceived and led the project. K.C.S., S.L.A., and P.G.B. wrote the manuscript with contributions and comments from all the authors.

\section{Additional information}

Supplementary Information accompanies this paper at https://doi.org/10.1038/s41467019-09486-2.

Competing interests: The authors declare no competing interests.

Reprints and permission information is available online at http://npg.nature.com/ reprintsandpermissions/

Journal peer review information: Nature Communications thanks the anonymous reviewers for their contribution to the peer review of this work.
Publisher's note: Springer Nature remains neutral with regard to jurisdictional claims in published maps and institutional affiliations.

(c) (i) Open Access This article is licensed under a Creative Commons Attribution 4.0 International License, which permits use, sharing, adaptation, distribution and reproduction in any medium or format, as long as you give appropriate credit to the original author(s) and the source, provide a link to the Creative Commons license, and indicate if changes were made. The images or other third party material in this article are included in the article's Creative Commons license, unless indicated otherwise in a credit line to the material. If material is not included in the article's Creative Commons license and your intended use is not permitted by statutory regulation or exceeds the permitted use, you will need to obtain permission directly from the copyright holder. To view a copy of this license, visit http://creativecommons.org/ licenses/by/4.0/.

(c) The Author(s) 2019 